\title{
Mapping adaptive capacity and smallholder agriculture: applying expert knowledge at the landscape scale
}

\author{
Margaret Buck Holland ${ }^{1} \cdot$ Sierra Zaid Shamer ${ }^{1}$ • \\ Pablo Imbach $^{2}$ - Juan Carlos Zamora ${ }^{2}$. \\ Claudia Medellin Moreno ${ }^{2}$ Efraín J. Leguía Hidalgo ${ }^{3}$ • \\ Camila I. Donatti ${ }^{4}$ M. Ruth Martínez-Rodríguez ${ }^{4}$. \\ Celia A. Harvey ${ }^{4}$
}

Received: 9 October 2015 / Accepted: 9 September 2016 / Published online: 26 September 2016

(C) The Author(s) 2016. This article is published with open access at Springerlink.com

\begin{abstract}
The impacts of climate change exacerbate the myriad challenges faced by smallholder farmers in the Tropics. In many of these same regions, there is a lack of current, consistent, and spatially-explicit data, which severely limits the ability to locate smallholder communities, map their adaptive capacity, and target adaptation measures to these communities. To explore the adaptive capacity of smallholder farmers in three data-poor countries in Central America, we leveraged expert input through in-depth mapping interviews to locate agricultural landscapes, identify smallholder farming systems within them, and characterize different components of farmer adaptive capacity. We also used this input to generate an index of adaptive capacity that allows for comparison across countries and farming systems. Here, we present an overview of the expert method used, followed by an examination of our results, including the intercountry variation in expert knowledge and the characterization of adaptive capacity for both subsistence
\end{abstract}

This article is part of a Special Issue on "Climate change impacts on ecosystems, agriculture and smallholder farmers in Central America" edited by Camila I. Donatti and Lee Hannah.

Electronic supplementary material The online version of this article (doi:10.1007/s10584-016-1810-2) contains supplementary material, which is available to authorized users.

Margaret Buck Holland

mholland@umbc.edu

1 Department of Geography \& Environmental Systems, University of Maryland, Baltimore County, 1000 Hilltop Circle, Baltimore 21250 Maryland, United States

2 Centro Agronómico Tropical de Investigación y Enseñanza (CATIE), Sede Central, 7170, Cartago, Turrialba 30501, Costa Rica

3 CCAFS Latin America, Centro Internacional de Agricultura Tropical (CIAT), KM 17 Recta Cali-Palmira, Palmira, Valle del Cauca, Colombia

4 The Betty and Gordon Moore Center for Science, Conservation International, 2011 Crystal Drive, Suite 500, Arlington, VA 22202, USA 
and smallholder coffee farmers. While this approach does not replace the need to collect regular and consistent data on farming systems (e.g. agricultural census), our study demonstrates a rapid assessment approach for using expert input to fill key data gaps, enable trans-boundary comparisons, and to facilitate the identification of the most vulnerable smallholder communities for adaptation planning in data-poor environments that are typical of tropical regions. One potential benefit from incorporating this approach is that it facilitates the systematic consideration of fieldbased and regional experience into assessments of adaptive capacity, contributing to the relevance and utility of adaptation plans.

\section{Introduction}

Smallholder farmers are a major priority group for climate change adaptation strategies, but such efforts are frequently confounded by a lack of spatial or contextual information on these subpopulations. Across the developing world, there are approximately 500 million smallholder farms that represent close to two-thirds of the rural population (IFPRI 2007) and are responsible for a significant portion of the world's agricultural production and economic output (Altieri et al. 2012). These farmers typically cultivate small areas, have few resources to maintain or increase productivity, live in environmentally fragile and remote locations, and generally lack access to technical assistance, credit, or government support (Vorley et al. 2012). Smallholder farmers are disproportionately affected by climate change, as they depend heavily on rain-fed agriculture and are therefore highly vulnerable to any changes in precipitation patterns. In addition, many smallholder farmers are food insecure, poor, and live in precarious conditions, frequently confronting situations of risk and uncertainty (Morton 2007; IFAD 2009). Given their high vulnerability to climate change, smallholder farming households and communities are a priority for climate change adaptation efforts worldwide.

In order to effectively target such efforts, policymakers, donors, and practitioners confront information barriers on the geographic distribution of smallholder farming systems and characteristics that may contribute to their overall vulnerability to climate change. In particular, decisionmakers want to better understand the relative adaptive capacity of smallholder farmers so that they can develop means of more explicitly enhancing adaptation in order to reduce overall vulnerability. Nonetheless, such information is extremely limited in many developing countries, and little is understood about the most current status of adaptive capacity within smallholder farming systems (although Bojórquez-Tapia and Eakin 2009 and Baca et al. 2014 have sought to capture this in the same study region).

The lack of information is in part due to the difficulty of obtaining data focused solely on smallholder farming communities, as a subset of the overall population in a region. Standard methods for assessing adaptive capacity rely on the collection of primary and secondary data. Primary data are used to define adaptive capacity within a specific context at the household- or community-scale. Secondary data, which are often government-generated, are used to estimate adaptive capacity locally or at broader scales (from sub-national to regional) (Holt-Gimenez 2002; Eakin et al. 2006; Alayon-Gamboa and Ku-Vera 2011; PNUD 2013; Baca et al. 2014). These approaches are often limited by data availability, quality, consistency, and reliability. In addition, challenges with bureaucratic processes, lack of clarity about data sharing policies, and poor documentation can limit utility and use of these data. Thus, there is a pressing need to sidestep these barriers and generate alternative approaches for mapping the characteristics of smallholder farming systems, assessing their vulnerability to climate change, and specifically understanding 
their adaptive capacity, which could be applied across data-poor countries to help improve the efficiency and targeting of climate adaptation strategies.

The objectives of this study were to (1) develop a participatory method to delineate distinct agricultural landscapes and map the adaptive capacity of smallholder farmers in data-limited contexts, (2) apply the method systematically to understand the adaptive capacity of smallholder farmers in three Central American countries (Costa Rica, Guatemala, and Honduras), and (3) use the information generated to understand the variation in adaptive capacity of smallholder farmers across farming systems and regions.

We focused on two farming systems, coffee and subsistence, which are the predominant forms of smallholder agriculture in the region (Baca et al. 2014). Central America is a relevant focus region because the effects of climate change are already evident: significant changes in precipitation, temperature, stream flow, and water availability have been observed over the last several decades and climate projections show further changes along these same trends (Aguilar et al. 2005; Giorgi 2006). Land availability severely limits the growth potential for agriculture in Central America, and climate change impacts further exacerbate those limits for both agricultural productivity and suitability (Aguilar et al. 2005; Läderach et al. 2010). Both types of farmers are highly vulnerable to climate change, due to their reliance on rain-fed agriculture. Subsistence farmers depend on their land for food security and limited income generation and typically have very limited access to financial or technical assistance. Smallholder coffee farmers are similarly vulnerable to climate change. Coffee is sensitive to temperature variability and temperature increase (Ovalle-Rivera et al. 2015), which can cause significant reductions in yield, aggravated by pest and disease outbreaks that can increase under changing climatic conditions (Baca et al. 2014; Bunn et al. 2015; Ovalle-Rivera et al. 2015; Avelino et al. 2015).

Our analysis was conducted at the landscape scale, with landscape defined as a geographic zone in which the mix of farming systems and related agricultural practices is distinct from surrounding areas. We did not predetermine the size of individual landscapes. Instead, we utilized expert knowledge and national context to inform the spatial dimensions of these units of analysis. Within each landscape, we focused on understanding the current profiles and farming systems of smallholder coffee and subsistence farmers. While the methodology was piloted in Central America, this approach can be similarly applied in any country interested in quickly and efficiently mapping populations of smallholder farming communities and characterizing their relative adaptive capacity, recognizing that local conditions within landscapes could vary.

We used the definition of adaptive capacity put forth by the Intergovernmental Panel on Climate Change (IPCC) as the "ability of a system to adjust to climate change to moderate potential damages, to take advantage of opportunities, or to cope with the consequences" (IPCC 2007). As a concept, adaptive capacity is often interchanged with coping ability and resilience (Smit and Wandel. 2006). As a measure, it is dynamic across space and time, with both local context and macro-scale conditions influencing the characterization of adaptability from the household to the global scale (Smit and Wandel. 2006). These traits of dynamism and cross-scalar influences help justify the inclusion of an analytical approach that integrates the input of experts who hold a view to the current local and regional setting. As such, this approach, along with similar methods to integrate rapid assessment, expert input, and geospatial technologies, represents a relatively low cost and effective tool for governments, donors and practitioners interested in using spatially-explicit information needed to assess the adaptive capacity of farming communities, identify those most vulnerable, recommend appropriate adaptation measures, and efficiently target the implementation of climate adaptation measures. 


\section{Materials and methods}

To map and characterize the adaptive capacity of smallholder farmers in unique agricultural landscapes, we developed a method that harnesses expert input across several stages of the process, and takes advantage of the breadth and depth of knowledge accumulated by national-level experts familiar with multiple production regions in each country. The expert mapping and classification process borrows from both rapid rural appraisal (RRA) methodologies associated with the fields of rural agricultural development and disaster risk management (Chambers 1981) and the burgeoning field of participatory geographic information systems (PGIS) (Brown and Kyttä 2014). The map plays a central role in the process of data collection, serving as a forum for dialogue and a negotiation space for validation of expert input. The following sections outline the main methodological steps used for data collection and analysis, both of which took place in June 2013 through May 2014.

\subsection{Landscape characterization survey}

Our first step involved the development of a standardized survey instrument to extract information related to general agricultural practices and socioeconomic characteristics of farming communities in a given landscape. This was administered to a group of experts with in-depth experience and knowledge of agricultural systems in each country.

Data collected included: average farm size, forms of land tenure (private, leased, communal, and informal), specific conventional or conservation practices associated with crop production (integrated pest management, use of synthetic fertilizers, chemical pesticides and disease control, riparian buffer conservation, different forms of irrigation, organic agriculture, mechanized labor, soil conservation, living fences, and re-planting or re-seeding of crops), type of market for crop sales (local, regional, national, international), types of on-farm assets (financial, social, physical, human, and natural) or services farmers might have access to, migration trends, social networks, alternative forms of household income, history of cultivation in the landscape, and the potential willingness of farmers to shift to other crops. Portions of the survey focused on either smallholder coffee farming (and producing) or subsistence farming within the landscape, including specific questions related to average size of landholding and land tenure characteristics. The survey also included questions about how extreme natural events (shock events) might have affected the landscape in the recent past (about five years), including the type of event, which cropping systems were impacted, and whether or not farmers received assistance. The survey instrument was pre-tested with colleagues from the Tropical Agricultural Research and Higher Education Center (CATIE), who would also be considered experts in certain regions. The full survey instrument for landscape characterization is included in Supplementary Online Material (SOM 1).

\subsection{Expert mapping interviews}

We conducted a total of 109 expert mapping interviews, which represented 44 different organizations across the three countries (Table 1). Our expert group had on average between 14 and 19 years in the field. Nearly three-quarters ( $74 \%)$ of the expert group were agronomists by training and practice. Another $11 \%$ were foresters, and the remaining $15 \%$ came from a variety of related fields (e.g. biologists, anthropologists, sociologists, veterinarians).

In each country, we used an extensive network of collaborators from the national technical offices of CATIE and various government agencies (ministries of agriculture, national coffee institutes, census and statistics institutes, and rural land development agencies), to identify 
Table 1 Summary of the institutional affiliations and years of experience for experts who participated in the landscape mapping, characterization, validation, and definition of adaptive capacity

\begin{tabular}{llcc}
\hline & Costa Rica & Guatemala & Honduras \\
\hline Total \# Experts & $\mathbf{3 2}$ & $\mathbf{4 0}$ & $\mathbf{3 7}$ \\
\# Experts by institutional affiliation & & & \\
- Associations of agricultural producers & 0 & 3 & 1 \\
- Centers of investigation and agricultural extension offices & 3 & 12 & 2 \\
- Independent consultants & 4 & 1 & 1 \\
- International corporations and corporate institutes & 1 & 1 & 2 \\
- National corporations & 13 & 2 & 0 \\
- Government agencies \& institutes & 8 & 9 & 21 \\
- Non-governmental organizations (NGOs) & 3 & 10 & 8 \\
- Universities & 0 & 2 & 2 \\
Ave \# years field experience & 15 & 14 & 19 \\
\# experts in validation workshops & 11 & 9 & 12 \\
\hline
\end{tabular}

experts who had both recent and multiple years of experience traveling and working in agricultural systems within sub-regions of their countries. We identified experts who could report on the agricultural practices and general characteristics across farming communities and then added additional experts through snowballing techniques.

In each one-on-one interview, we first reviewed a standard base map (1:500,000 scale), which included the most current land use and land cover data available for the country of focus: Costa Rica (2010), Guatemala (2003), and Honduras (2009). We also presented reference maps that included spatial layers of roads, political/ administrative divisions, rivers and other bodies of water, populated centers, and national protected areas networks to facilitate the identification of the landscapes. Then, we asked experts to identify regions where they had spent at least two years offering extension services or conducting project work. Within these regions, each expert would then begin delineating polygons to represent unique agricultural landscapes and respond to the survey for each landscape drawn. The typical duration of an interview was one and a half hours, and experts were able to contribute two to three landscapes on average. Upon completion of this first round of one-on-one interviews, experts defined 177 landscape polygons, including 36 for Costa Rica, 54 for Guatemala, and 87 for Honduras.

\subsection{Validation workshops}

We convened three workshops in each country in mid-2013 to: (a) review the previously delineated landscapes and survey results from landscape characterization that resulted from the one-on-one interviews, (b) resolve areas of landscape overlap, and (c) attempt to fill in gaps in each country. We invited experts from the original one-on-one mapping interviews and additional experts with similar expertise and profiles. Following the validation workshops, we identified gaps for each country (e.g. in the Petén region of Guatemala and the Sarapiquí region of Costa Rica) and utilized our existing networks to identify additional experts with knowledge of those regions, whom we then connected with for additional mapping interviews. 
Table 2 Asset categories, associated variables, and expert majority agreement on relationship with adaptive capacity

\begin{tabular}{|c|c|c|}
\hline $\begin{array}{l}\text { Asset } \\
\text { Category }\end{array}$ & Associated variables for measure of adaptive capacity & $\begin{array}{l}\text { Increased (+) / Lowered } \\
(-) \\
\text { Adaptive Capacity }\end{array}$ \\
\hline \multirow[t]{5}{*}{ Financial } & Investments to improve crop production: & \\
\hline & $\begin{array}{l}\text { - Fertilizers, pesticides } \\
\text { - Soil preparation / tilling } \\
\text { - Irrigation (high-input) }\end{array}$ & + \\
\hline & Access to: & \\
\hline & $\begin{array}{l}\text { - Credit } \\
\text { - Subsidies } \\
\text { - Diverse income sources }\end{array}$ & + \\
\hline & Receive remittances & - \\
\hline \multirow[t]{3}{*}{ Social } & Migration-related trends: & \\
\hline & $\begin{array}{l}\text { - Recent migrants (last } 5 \text { years) } \\
\text { - Male population has out-migrated, leaving majority female-headed } \\
\text { households } \\
\text { - Household heads migrate seasonally for work outside zone } \\
\text { - Youth population has out-migrated, leaving elderly as household head }\end{array}$ & - \\
\hline & Receive assistance after extreme events & - \\
\hline \multirow[t]{4}{*}{ Physical } & Mitigation of crop damage: & \\
\hline & $\begin{array}{l}\text { - chemical control of pests and disease } \\
\text { - integrated pest management (IPM) }\end{array}$ & + \\
\hline & Access to: & \\
\hline & $\begin{array}{l}\text { - market or small grocery store for sales } \\
\text { - storage for crop product } \\
\text { - crop transportation to market } \\
\text { - agricultural machinery/equipment }\end{array}$ & + \\
\hline Human & Access to human labor & + \\
\hline Natural & Implements soil conservation practices & + \\
\hline
\end{tabular}

\subsection{Characterizing and measuring adaptive capacity}

\subsubsection{Expert online survey}

In order to define an overall index measure of adaptive capacity, we distributed an interactive online survey to all expert participants. Each was asked to: (1) assign twenty variables from the original landscape characterization survey into the five asset categories (natural, human, social, physical, and financial) and (2) qualify each variable as either contributing to a low or high degree of adaptive capacity (Table 2). We selected these asset categories and the set of potential variables from the survey based on similar studies (Bojórquez-Tapia and Eakin 2009; Eakin et al. 2011; Baca et al. 2014). This expert-driven categorization of variables resulted in an uneven distribution across asset categories. For example, experts consistently assigned six variables to the physical asset category and five to the social asset category, whereas human and natural capital categories were only assigned one variable each. 


\subsubsection{Calculation of index}

Based on this expert input, we were able to construct an index measure for adaptive capacity, which we could also utilize to compare relative adaptive capacity scores across all three countries. First, we assigned variables to an asset category based on majority agreement of experts from the online survey. Second, we re-coded the values so that a value of 1 indicates high adaptive capacity, and 0 indicates low adaptive capacity. In this way, when survey responses for each landscape were summed, a high total number indicated a high adaptive capacity, while a lower number indicated a lower adaptive capacity. We further simplified the adaptive capacity index to fit within a range of $0-5$ points (with 0 indicating a low adaptive capacity and 5 indicating a high adaptive capacity), where each of the five asset categories contributes equally (one point) to the index score for that landscape.

If there was too little information for a specific asset category, we took a conservative approach in calculating the index. We never assumed that, in the absence of data, variables contributed to a high adaptive capacity. Because the landscape characterization survey included specifications about both smallholder coffee and subsistence agriculture, many of the resulting landscapes in our study had multiple adaptive capacity scores, one for each type of farming system. All information collected from our group of experts was compiled into a master database and digitized for analysis in a geographic information system (GIS). With this, we were able to generate descriptive statistics and cross-group (farming systems and countries) comparisons.

\section{Results}

Experts mapped a total of 299 distinct agricultural landscapes (75 for Costa Rica, 103 for Guatemala, and 121 for Honduras; Fig. 1) and characterized components of adaptive capacity for $249(83 \%)$ of these landscapes where smallholder coffee or subsistence agriculture systems were present. Average sizes of landscapes were $392 \mathrm{~km}^{2}$ in Costa Rica, $799 \mathrm{~km}^{2}$ in Guatemala, and $1123 \mathrm{~km}^{2}$ in Honduras. Spatial overlap for expert-defined landscapes was highest for Guatemala and Honduras; there was very little overlap in Costa Rica. Even considering these overlaps, the percent of agricultural and forest land area within each country that experts mapped as within distinct landscapes was $58 \%$ in Costa Rica, $90 \%$ in Guatemala, and $93 \%$ in Honduras. This represents the majority of the rural landscape in each country, especially when considering the spatial extent of predominantly forested protected areas.

\subsection{Profiles of subsistence farming and smallholder coffee systems}

For subsistence agriculture in our set of expert-defined landscapes, across all three countries, the main crop production was basic grains, the most common form of tenure was as an individual (private) landowners, and farm plots were typically less than two hectares. Within the broader category of basic grains for subsistence agriculture, experts in Guatemala and Honduras consistently defined it as representing a cropping mix of maize and beans, while for Costa Rica subsistence farming suggested a diverse grouping of vegetables, pulses, and grains. For all three countries, the experts we interviewed associated subsistence farming with cultivation where the output is tied mainly to a combination of on-farm consumption with some product directed for sale at local markets. Experts defined smallholder coffee as similarly 


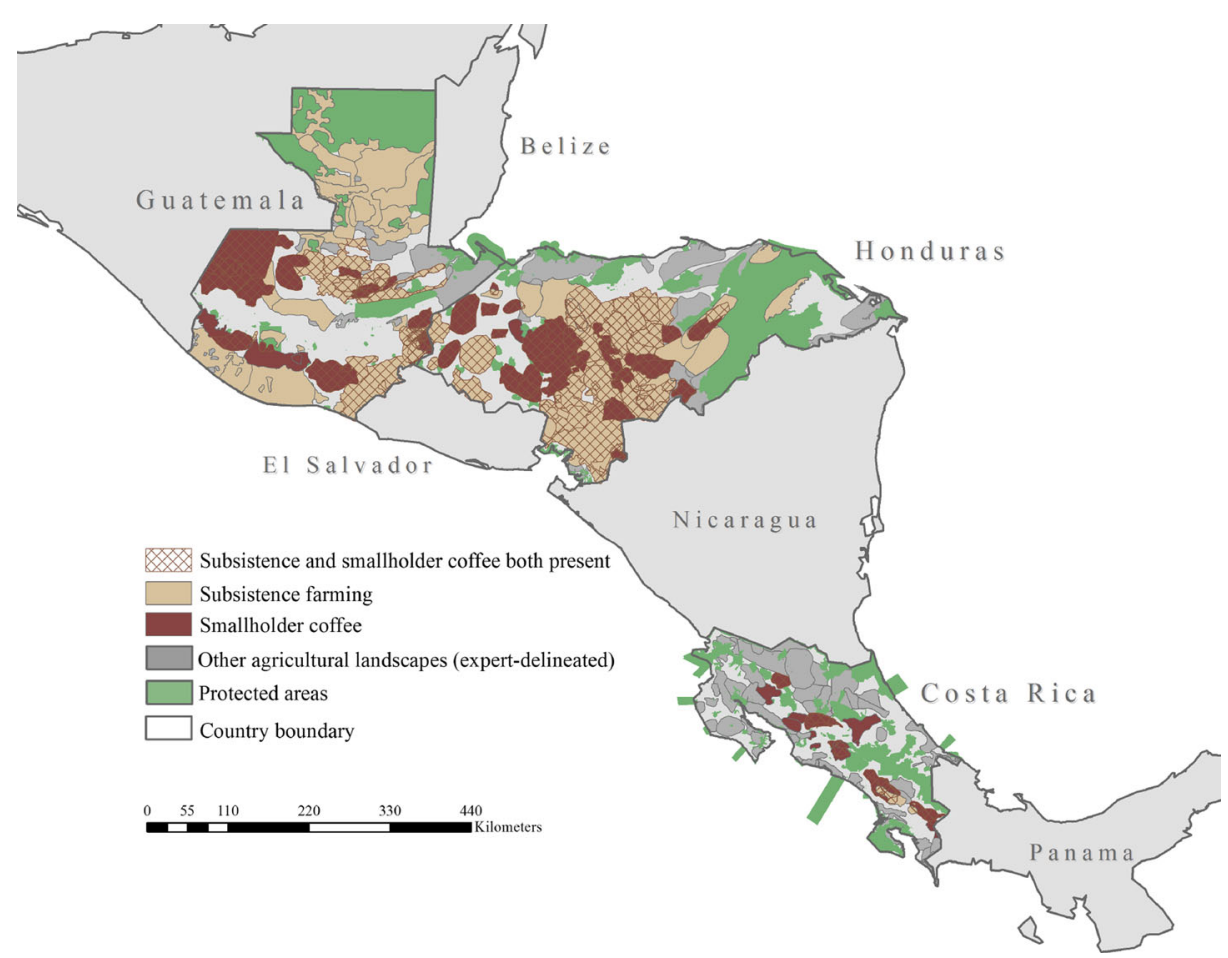

Fig. 1 Expert-mapped agricultural landscapes for study area countries: Costa Rica, Guatemala, and Honduras

having small average farm sizes (less than two hectares), primarily held by individual landowners, and with production directed to local, national, and even international markets (typically through collection centers).

Experts listed coffee as the dominant cropping form in $20 \%(n=15)$ of landscapes in Costa Rica. When an expert identified coffee production in a landscape, it was typically the sole form of production and land use, with pasture, vegetables, and basic grains only occasionally listed as representing a relatively small proportion of the landscape area. Only in a few landscapes in Costa Rica does smallholder coffee appear as a secondary cropping system (based on area cultivated), and that is primarily in landscapes where pasture is the dominant land use. For our set of expert-mapped landscapes in Costa Rica, there is not a single instance where basic grains (subsistence agriculture) are listed as the main agricultural use.

The opposite was the case for Guatemala and Honduras. In Guatemala, our expert respondents mapped more landscapes where the primary agricultural practice is subsistence agriculture for basic grains (37 landscapes, or $36 \%$ ) rather than coffee production (21 landscapes, or $20 \%$ ). For Honduras, experts listed subsistence agriculture as the primary system within 34 landscapes ( $28 \%$ ) while smallholder coffee production was dominant for 22 landscapes $(18 \%)$. From landscapes in both Guatemala and Honduras, we observed more instances where both basic grains and coffee intermix within the same landscape, along with forested land and pasture (Fig. 1). In Guatemala, cardamom cropping systems emerged as an additional example of smallholder crops, often mixed with coffee and basic grains in the central-western region of the country. 
(a) Subsistence agriculture
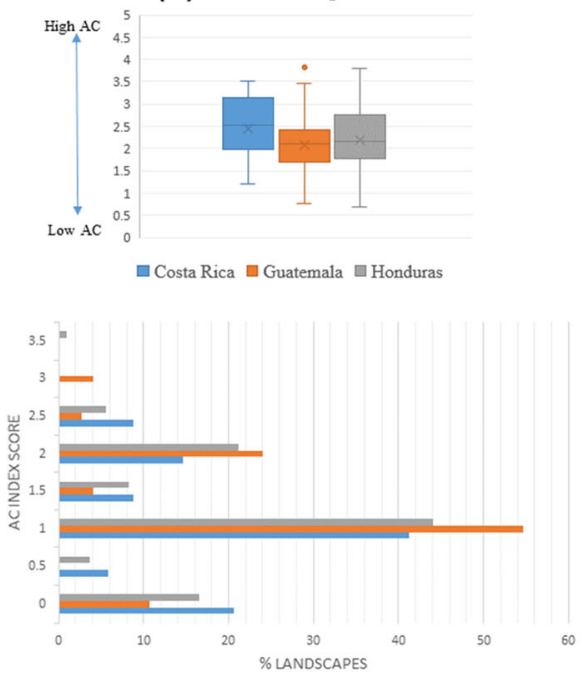

(b) Smallholder coffee

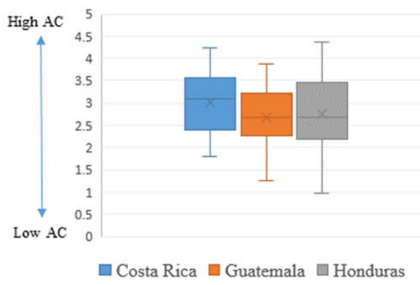

ECosta Rica Guatemala

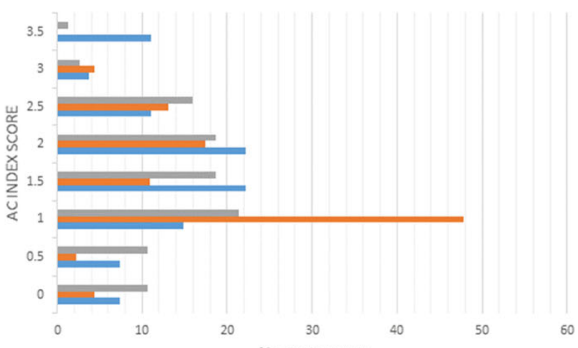

Fig. 2 Distribution of adaptive capacity index scores for a subsistence agriculture and $\mathbf{b}$ smallholder coffee across all three study countries

\subsection{Characteristics of adaptive capacity}

Even though the adaptive capacity index went from 0 to 5 , none of the landscapes in the three countries received an index higher than 4.37. Overall, adaptive capacity scores for smallholder coffee systems were higher (mean of $2.77+/-0.1 \mathrm{SE}$ ) than those for subsistence agriculture (mean of $2.17+/-0.07 \mathrm{SE}$ ), ranging between $0.97-$ 4.37 (smallholder coffee) and 0.69-3.83 (subsistence). Of the three countries, Costa Rican landscapes scored the highest average adaptive capacity for both smallholder coffee and subsistence, followed by Honduras, and then Guatemala (Fig. 2). Honduran landscapes exhibited the biggest range in adaptive capacity scores for both farming systems, as compared with Costa Rica and Guatemala.

In Costa Rica, adaptive capacity for subsistence farming was lowest in landscapes situated along the Nicaraguan and Panamanian borders (typically more remote in terms of access to markets), and on the Nicoya Peninsula (Fig. 3). In Guatemala, the landscapes with lowest adaptive capacity for both smallholder systems were located within the south-eastern region of the country, also known as the "Corredor Seco", or Dry Corridor, as well as up near the more remote Petén region. For Honduras, low adaptive capacity scores for both smallholder systems were clustered in the central-western portion of the country within La Paz, Intibuca, and Comayagua, and El Paraiso in the south (Fig. 3). These also align with the location of the Corredor Seco in Honduras (Van der Zee Arias et al. 2012).

When examining the relative contribution of each asset category to the adaptive capacity score across landscapes and within each country, there were several key differences. First, smallholder coffee systems exhibited higher physical capital and increased access to credit (financial capital) than subsistence farming, and this was consistent across all three countries. In Costa Rica, natural capital contributed more to higher adaptive capacity for smallholder coffee than for subsistence farmers. Second, experts in Costa Rica and Honduras indicated that 


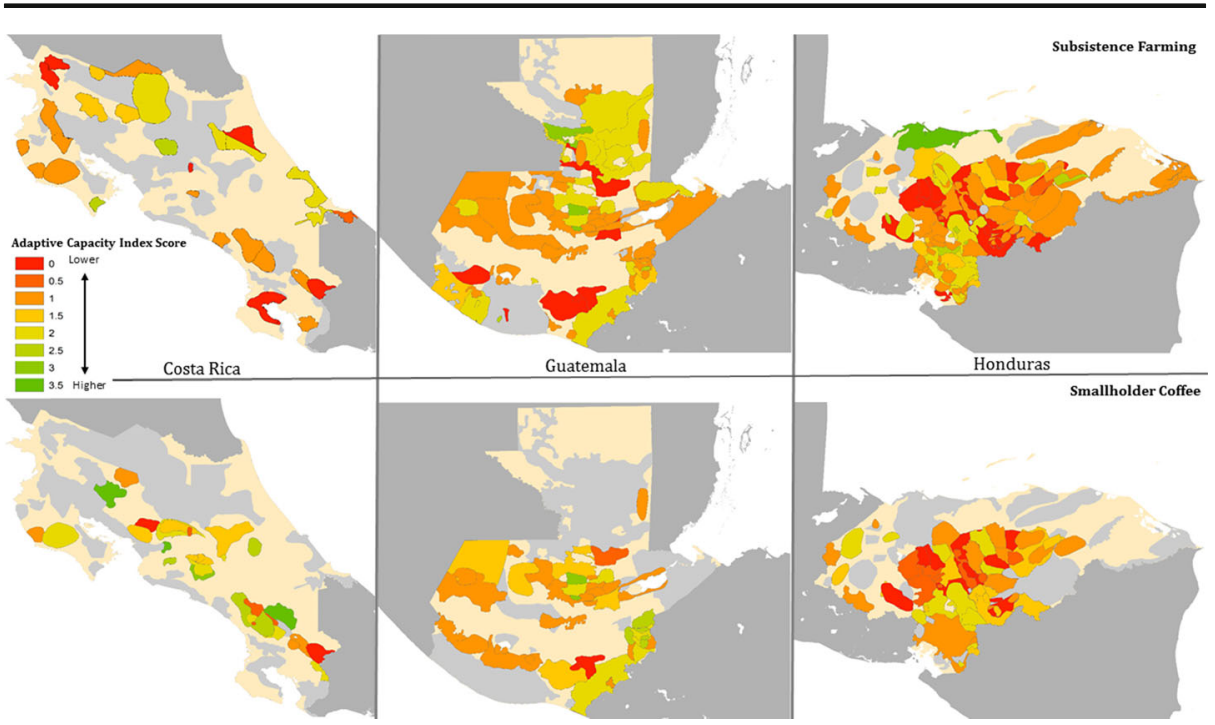

Fig. 3 Spatial distribution of adaptive capacity scores for subsistence farming and smallholder coffee across expert-defined landscapes in Costa Rica, Guatemala, and Honduras

remittances comprised an important source of household income in the majority of subsistence agriculturalist and smallholder coffee communities (61\% of landscapes in Costa Rica, $71 \%$ in Honduras). However, in Guatemala, this was the case for fewer than half of all landscapes. Finally, migration dynamics among smallholder farming landscapes differed somewhat across the three countries. Within Honduras, experts indicated that the main migration trend present in smallholder farming communities was a recent flow of in-migration. While this was also the case for the majority of landscapes in Costa Rica and Guatemala, the other common trend for these countries was for household women to take over the role of head-of-household while men practiced temporary migration for work.

\subsection{Shocks and responses among smallholder farming systems}

For all three study countries, experts selected disease and pest outbreaks as the type of shock that most affected smallholder coffee systems, ranging from 50 to $63 \%$ of landscapes where smallholder coffee is dominant. This comes as no surprise, given the effects of the coffee rust outbreak across Central America, most notably affecting crops in 2012 (Cressey 2013; FEWSNET 2016). Disease outbreaks can be characterized as environmental or climate-induced shocks that follow a fast pathway, as compared with slower onset shocks, such as drought (Gray and Bilsborrow 2013). Drought and flooding factored closely behind disease and pest outbreaks for Guatemala and Honduras, and in both these countries, drought primarily impacted subsistence farming. Overall, experts indicated that landscapes received external assistance to help respond to shocks most often when impacted by disease and pest outbreaks, as compared with drought or flooding events. Of the three countries, Costa Rica had the highest proportion of landscapes that received outside assistance, and more specifically in response to disease and pest outbreaks. Guatemala registered as experiencing the lowest degree of assistance in response to any form of shock (fewer than $25 \%$ of landscapes). 


\section{Discussion}

\subsection{Methodological assessment}

Our methodology, which used expert mapping and expert input to assess components of adaptive capacity, allowed us to systematically characterize agricultural landscapes and define landscape-scale adaptive capacity for smallholder farmers in all three countries, despite the lack of secondary data sources and data gaps. Experts provided a wealth of information on the averaged conditions of farming systems and communities within individual landscapes and their relative adaptive capacity based on their long-term experiences in these regions. In addition, experts helped identify various elements factored into determining farmer adaptive capacity within a country-level context, allowing us to create an adaptive capacity index to compare across all landscapes. Our methodology was therefore not only useful for characterizing individual landscapes but also scalable for both cross-landscape comparisons of adaptive capacity within individual countries and cross-national comparisons.

This approach could be easily applied to other developing countries with poor or incomplete data on agricultural production, farmer livelihoods and adaptive capacity, as it depends solely on expert input, workshops, online surveys, and someone to guide the process. The approach provides a combination of both quantitative and qualitative information. As such, this methodology offers an important step forward for countries interested in understanding the adaptive capacity of different communities and identifying which regions can be targeted for more indepth investigations of the vulnerability of smallholder agriculturalists to climate change.

Our experiences point to three considerations to ensure successful implementation of this approach. First, it is important that the right set of experts are identified and involved in the process. Experts involved should have both long-term and current in-field experience and interaction with these farming communities as well as experience across sub-national regions. We found in-depth understanding of agricultural practices to also be important, but this was not necessarily tied to the expert's field of expertise. For this study, the selection of field experts working at a sub-national or regional level was most appropriate for our scale of analysis. This sub-national scale can be challenging for both spatial and contextual analysis. Our set of expert respondents could, for the most part, be defined as connectors or intermediary actors who communicate across scales of interest.

Second, there is a need to have a formal process for reconciling overlapping or contested information. Our approach of holding one-day map validation workshops in each country allowed for us to resolve overlaps in a systematic way. Incorporating a larger group of experts, served as a way to reduce potential expert input bias and provide more conservative and consensus characterizations of landscapes. Finally, it is important that the results of the mapping exercises are validated with a broad set of experts to ensure their scientific robustness and external validity of the results.

Bias is an important consideration, especially when considering research that involves valuation or the creation of indices or measures of well-being. Ultimately, we would argue that there is no way to completely eliminate bias from this type of research. Even when utilizing public domain data for analysis, there is inherent bias in the selection of variables to include in measures of adaptive capacity, as well as bias present when developing decision rules for ranking those variables. As a team, our strategy was to prioritize reducing researcher bias at every possible step, and we shifted potential bias to our expert respondents who have more in-depth and local experience. 


\subsection{Factors that affect the adaptive capacity of smallholder farmers in central American landscapes}

Our results characterize smallholder coffee and subsistence farming systems for three countries in a region where climate change-related trends such as extended dry seasons, shorter and more intense rainy seasons, and related incidents of crop pest and disease outbreaks are currently impacting agricultural yields and smallholder livelihoods. This translates to higher food insecurity within the region, especially for those communities already located within the Corredor Seco (Van der Zee Arias et al. 2012) and impacted by the 2015 drought, such as those within Guatemala and Honduras (FEWS-NET 2016). Across the three countries, our experts strongly associated higher adaptive capacity with increased access to markets, credit, on-farm labor, investments in soil conservation, secure land tenure, and less dynamic migration. Overall, these characteristics align closely with what we understand from the literature on assets, adaptation, and coping strategies for smallholder coffee and subsistence farmers in this region (Campos et al. 2014; Alayon-Gamboa and Ku-Vera 2011; Altieri and Koohafkan 2009; Eakin et al. 2006).

Interestingly, there were two instances where the expert characterization and valuation diverged from our understanding from the literature. In the first case, the majority of experts categorized "receives remittances" as indicative of lower adaptive capacity. Having access to a remittance-based stream of income could, on average, increase a household's capacity to respond to shocks or a community's overall resilience simply by representing a form of income that is not tethered to land use, thereby decreasing vulnerability to localized shock events, such as those that might result from climate change (Ellis 2000; Bebbington and Perreault 1999). Depending on the context, remittances can result in more input-heavy and intensified agricultural production or relieve the household's need to focus on agriculture as the primary livelihood strategy (Lambin and Meyfroidt 2010). This is a relevant evidence gap to address within Central America, given the economic contribution remittances make within many countries in the region. Our set of expert-defined landscapes for Honduras ranked highest in terms of receiving remittances, a characteristic that is matched at the nationalscale with remittance in-flows representing more than $17 \%$ of GDP (World Bank 2016).

In the second instance, the majority of experts perceived the variable "receiving external assistance" after shock events to represent a certain level of dependence and inability to mobilize internal coping strategies to respond and adapt post-shock. Whereas our initial assumption had been that receiving external assistance would represent some degree of improved access to services and strengthened governance, our expert group viewed this characteristic as indicative of greater need and lower adaptive capacity. It is this divergence between the assessment of experts and our own a priori assumptions about the characterization of adaptive capacity that underscores the value of incorporating local context and a participatory process when attempting to characterize complex aspects of adaptive capacity.

Smallholder coffee farming communities consistently ranked higher in our overall expert assessment of adaptive capacity than subsistence agriculture. Despite the translation by experts of "receiving external assistance" as signifying an inability to cope, subsistence agriculture in Guatemala was scored as having low adaptive capacity, even when indication of external assistance was absent. For both Guatemala and Honduras, climate change will continue to exacerbate existing stresses (e.g. drought conditions) that take a particularly heavy toll in regions where subsistence agriculture is dominant. This, along with further predicted decreases in maize production and yields throughout northern Central America (FEWS NET 2016), 
translates to a need for policymakers and donors to target strategies for subsistence farmers in both countries that help them at the household level to diversify agricultural production and income and increase access to services to bolster social capital within communities.

While smallholder coffee exhibits higher adaptive capacity in our study, as a farming system, it still poses a set of unique challenges for policymakers needing to design and prioritize adaptation strategies. The investment made by coffee farmers includes time and labor in addition to financial investment, and the entire system is strongly tethered to the land. Therefore, it is incredibly hard to reduce the exposure of smallholder coffee systems to climate change or to recommend a shift from one form of agricultural production to another. The connection that smallholder coffee systems have to more national and international markets, while potentially beneficial for increasing financial capital, can also make these farmers more vulnerable to economic shocks.

While our study finds that smallholder coffee and subsistence farming systems share many similar characteristics, recommendations on how to more efficiently target and increase the adaptive capacity of coffee farmers could look quite different than those for subsistence agriculturalists. Supporting strategies for subsistence agriculturalists to adapt in a changing climate might fall within the responsibility of the state and related government institutions. In the case of smallholder coffee, policymakers could target the involvement of nongovernmental actors along the commodity chain, as well as more international donors, to help increase aspects of human and financial capital that allow coffee farmers to more easily adapt in place and respond to disease outbreaks on their farm.

In addition, newer strategies are emerging that focus on avoiding the shift to adaptation strategies that emphasize higher inputs of chemicals and mechanization as a way of mitigating future climate-induced shocks. Such strategies invest in strengthening agricultural extension programs to promote adaptation practices for smallholders that are ecosystem-based. This could generate important short-term livelihood benefits as well as long-term benefits through ensuring improved ecosystem health (Vignola et al. 2015). Such ecosystem-based adaptation strategies recognize the benefits that local ecosystems can yield in terms of smallholder crop production, and buffers from the impacts of negative environmental or climate shocks. Evidence is still building on the effects of ecosystem-based adaptation (EbA) strategies on adaptive capacity. Ecosystem-based strategies promote the adoption of agricultural practices that are already recognized to benefit both smallholder coffee and subsistence agriculturalists and their crop production in the long-term (Vignola et al. 2015).

\section{Conclusion}

The methodology we have used in this study can be replicated, revised, and explored at different spatial scales and geographies. It can help decision-makers in Central America as well as other developing regions, where smallholder farmers are key constituents of the population and limited information is available on their adaptive capacity. While this approach does not replace the need for collecting reliable and consistent data on these farming systems for the public domain (e.g. agricultural censuses), it can work to complement and ultimately enhance analysis of those data by systematically integrating and summarizing the contextual knowledge of local experts. We see the approach as one that is transferable to other countries that face critical data gaps, while the involvement of experts helps account for sub-national contexts.

The results from this expert-informed mapping and characterization of adaptive capacity for smallholder coffee and subsistence farmers provide policymakers, donors and practitioners 
with detailed, spatially-explicit, and up-to-date information not only on where these farming systems are located, but also on farmers' specific agricultural practices and ability to cope in response to shocks, such as those induced by climate change. While it is challenging for countries to effectively reduce the vulnerability of their more marginalized populations through focusing on their degree of exposure or sensitivity (as other recognized components of vulnerability), policymakers can leverage attention and assistance to increase the adaptive capacity of these populations. A rapid mapping assessment and farming system characterization, such as the one we present here, can provide guidance on where to focus adaptation plans at a national level and how to strategically target and implement adaptation efforts within smallholder farming communities to improve their ability to cope and adapt in place.

Acknowledgments This study was conducted as part of the CASCADE project ("Ecosystem-based Adaptation for Smallholder Subsistence and Coffee Farming Communities in Central America"). This project is part of the International Climate Initiative (ICI). The German Federal Ministry for the Environment, Nature Conservation, Building and Nuclear Safety (BMUB) supports this initiative on the basis of a decision adopted by the German Bundestag.

Open Access This article is distributed under the terms of the Creative Commons Attribution 4.0 International License (http://creativecommons.org/licenses/by/4.0/), which permits unrestricted use, distribution, and reproduction in any medium, provided you give appropriate credit to the original author(s) and the source, provide a link to the Creative Commons license, and indicate if changes were made.

\section{References}

Aguilar E et al (2005) Changes in precipitation and temperature extremes in central America and northern South America, 1961 - 2003. J Geophys Res 110:D23107. doi:10.1029/2005JD006119

Alayon-Gamboa JA, Ku-Vera JC (2011) Vulnerability of smallholder agriculture in Calakmul, Campeche, Mexico. Indian J Tradit Knowl 10(1):125-132

Altieri, M.A., P. Koohafkan. 2009. Enduring Farms: Climate Change, Smallholders and Traditional Farming Communities. Environment and Development Series No. 6, Third World Network, Penang Malaysia, 72 pp.

Altieri MA, Funes-Monzote FR, Petersen FRP (2012) Agroecologically efficient agricultural systems for smallholder farmers: contributions to food sovereignty. Agron Sustain Dev 32(1):1-13

Avelino J, Cristiancho M, Georgiu S, Imbach P, Aguilar L, Bornemann G, Laderach P, Anzueto F, Hruska AJ, Morales C (2015) The coffee rust crises in Colombia and central America (2008-2013): impacts, plausible causes and proposed solutions. Food Secur 7(2):3030-3321. doi:10.1007/s12571-015-0446-9

Baca M, Läderach P, Haggar J, Schroth G, Ovalle O (2014) An Integrated Framework for Assessing Vulnerability to Climate Change and Developing Adaptation Strategies for Coffee Growing Families in Mesoamerica. PLoS One 9(2):e88 463

Bebbington A, Perreault T (1999) Social capital, development, and access to resources in highland Ecuador. Econ Geogr 75:395-418. doi:10.1111/j.1944-8287.1999.tb00127.x

Bojórquez-Tapia, L.A. and H. Eakin. 2009. ANP Modeling of Complex Socio-Environmental Systems: Adaptive capacity of smallholder coffee systems in mesoamerica. Proceedings of the International Symposium on the Analytical Hierarchy Process 2009. 10 pp

Brown G, Kyttä M (2014) Key issues and research priorities for public participation GIS (PPGIS): a synthesis based on empirical research. Appl Geogr 46:122-136

Bunn C, Laderach P, Ovalle O, Kirschke D (2015) A bitter cup: climate change profile of global production of Arabica and Robusta coffee. Clim Chang 129(1-2):89-101

Campos M, Velázquez A, McCall M (2014) Adaptation strategies to climatic variability: a case study of smallscale farmers in rural Mexico. Land Use Policy 38:533-540

Chambers R (1981) Rapid rural appraisal: rationale and repertoire. Public Adm Dev 1:95-106. doi:10.1002/pad. 4230010202

Cressey (2013) Coffee rust regains foothold. Nature 493:587 Jan 31, 2013

Eakin H, Tucker C, Castellanos E (2006) Responding to the coffee crisis: a pilot study of farmers' adaptations in Mexico, Guatemala and Honduras. Geogr J 172(2):156-171 
Eakin H, Bojórquez-Tapia LA, Monterde Diaz R, Castellanos E, Haggar J (2011) Adaptive capacity and socialenvironmental change: theoretical and operational modeling of smallholder coffee systems response in Mesoamerican Pacific rim. Environ Manag 47:352-367

Ellis F (2000) The determinants of rural livelihood diversification in developing countries. J Agric Econ 51:289302. doi:10.1111/j.1477-9552.2000.tb01229.x

FEWS-NET. (2016). Central America Regional Supply and Market Outlook. Famine Early Warning System Network. http://www.fews.net/sites/default/files/documents/reports/LAC\%20SO_20160429 FINAL.pdf Last accessed 05/27/2016

Giorgi F (2006) Climate change hot-spots. Geophys Res Lett 33:L08707. doi:10.1029/2006GL025734.

Gray C, Bilsborrow R (2013) Environmental influences on human migration in rural Ecuador. Demography 50(4):1217-1241

Holt-Gimenez E (2002) Measuring farmers' agroecological resistance after hurricane Mitch in Nicaragua: a case study in participatory, sustainable land management impact monitoring. Agric Ecosyst Environ 93:87-105

IFAD. (2009). Annual Report. International Fund for Agricultural Development (IFAD). http://www.ifad.org/ pub/ar/2009/e/index.htm

IFPRI. (2007). Annual Report. International Food Policy Research Institute (IFPRI). doi:10.2499/ 0896299201AR0n708

IPCC. (2007). AR4 http://www.ipcc.ch/publications_and_data/ar4/wg2/en/annexessglossary-a-d.html

Läderach, P.; Haggar, J.; Lau, C.; Eitzinger, A.; Ovalle, O.; Baca, M.; Jarvis, A.; Lundy, M. (2010). Mesoamerican coffee: Building a climate change adaptation strategy. CIAT Policy Brief no. 2. Centro Internacional de Agricultura Tropical (CIAT), Cali, Colombia. $4 \mathrm{p}$

Lambin E, Meyfroidt (2010) Land use transitions: Socio-ecological feedback versus socio-economic change. Land Use Policy 27(2):108-118

Morton JF (2007) The impact of climate change on smallholder and subsistence agriculture. Proceedings of the National Academies of Sciences (PNAS) 104(50):19680-19685

Ovalle-Rivera O, Laderach P, Bunn C, Obersteiner M, Schroth G (2015) Projected shifts in Coffea arabica suitability among major global producing regions due to climate change. PLoS One 10(4):e0124155. doi:10. 1371/journal.pone.0124155

PNUD (2013) Programa de las Naciones Unidas para el Desarrollo (PNUD). Gestión de riesgos climáticos para la agricultura de pequeña escala en Honduras Nueva York. Dirección de Prevención de Crisis y de Recuperación del PNUD, NY

Smit B, Wandel. J (2006) Adaptation, adaptive capacity and vulnerability. Glob Environ Chang 16:282-292

Van der Zee Arias A, van der Zee J, Meyrat A, Poveda C, Picado L (2012) Estudio de caracterización del Corredor Seco Centroamericano. Tomo 1. Food and Agriculture Organization (FAO) of the United Nations, Tegucigalpa, p. 92 pp

Vignola R, Harvey CA, Bautista-Solis P, Avelino J, Rapidel B, Donatti C, Martinez R (2015) Ecosystem-based adaptation for smallholder farmers: Definitions, opportunities and constraints. Agric Ecosyst Environ 211: 126-132

Vorley B, Cotula L, Chan M-K (2012) Tipping the balance. Policies to shape agricultural investments and markets in favor of small-scale farmers. Research Report, IIED-Oxfam

World Bank. 2016. Migration and Remittances Data. http://www.worldbank.org/en/topic/ migrationremittancesdiasporaissues/brief/migration-remittances-data. Last accessed: 05/27/16 